\title{
János Barcsák
}

\section{Creativity, Singularity, Ethics in Pope's Essay on Criticism}

\begin{abstract}
This paper discusses Pope's Essay on Criticism in terms of Derek Attridge's theory of creativity. It argues that Pope's text is fundamentally based on the same commitment to the other that Attridge describes as constitutive of the singularity of literature and hence the 300-year-old Essay is a vital text which communicates itself to the present in significant ways. The success of poetry for Pope depends primarily on an appropriate relation to nature and the first chapter of this paper argues that the way Pope describes this relation is very similar to Attridge's description of the relation to the other. The three subsequent chapters discuss how Pope's concept of "expression" continues this theme and describes the pitfalls as well as the success of relating to nature as the other. The last two sections discuss the Essay's treatment of the rules. It is shown that the way the rules are presented in the Essay reflects Pope's fundamental ethical commitment no less than his concepts of nature and "true expression" do.
\end{abstract}

In his book, Reconstructing Criticism: Pope's Essay on Criticism and the Logic of Definition, Philip Smallwood reads Pope's Essay in the context of our modern perplexities about the concept of criticism. ${ }^{1}$ He argues that the poem can "define a concept of 'criticism' able to penetrate our own thwarted struggles to say what criticism is." 2 The definition Smallwood traces in the Essay can thus correct some of our modern misconceptions about criticism and provide a framework in which all the important elements that have been associated with criticism fall into place and become interpreted as parts of an untotalizable whole. Smallwood's insights about criticism and his interpretation of Pope's Essay are interesting enough in themselves; however, what I find even more significant than these - and what I would like to emulate in this paper - is that he presents an image of Pope as a vital poet.

Since David Fairer's book on Pope's Imagination ${ }^{3}$ this aspect of Pope's achievement has been somewhat neglected. From the mid-1980's new readings of

1. Philip Smallwood, Reconstructing Criticism: Pope's Essay on Criticism and the Logic of Definition (Lewisburg: Bucknell University Press, 2003).

2. Smallwood, p. 151.

3. David Fairer, Pope's Imagination (Manchester: Manchester University Press, 1984).

The AnaChronisT 17 (2012/13) 28-61 ISSN 1219-2589 (print) ISSN 2063-126X (web) 
his poetry, equipped with the techniques and strategies of "cultural studies" and "theory," started to challenge the ideological positions that Pope apparently adopts by pointing out how the texts undermine these ideologies and by drawing attention to the troubling incongruities under the sugary surface of the neat heroic couplets. ${ }^{4}$ This approach was countered by "the opposite image of Pope as embattled humanist, employing as precept and example his considerable poetic talents to turn the tide of cultural mediocrity that he saw as threatening to overtake his society." 5 These approaches have no doubt produced many a valuable insight into Pope's poetry over the last two decades. However, they both tend to neglect Pope's significance for the present, the fact that his poetry raises issues and offers solutions that are of vital importance in our modern experience, as well.

This is why it is particularly refreshing to encounter an approach like Smallwood's which assumes that - besides its historical and cultural embeddedness - Pope's threehundred-year-old Essay on Criticism also communicates itself to the present. To account for this communicative success Smallwood needs to postulate an informing vision which underlies and organizes all the disparate elements of the poem; a unified vision which exists beyond the multiplicity and apparent incongruity of the statements of the text. It is this unified vision which gets communicated to our present-day experience even in spite of the fact that it is formulated in the material of rather heterogeneous statements and contemporary allusions. To postulate such an "organic unity" 6 or, to use Smallwood's term, "disunified unity,"7 might appear to be an illegitimate step in the light of much of modern Pope scholarship, which has assumed and convincingly argued for the fundamental disunity of Pope's texts. However, as Smallwood's results have clearly demonstrated, the opposite assumption can also be fruitful; and what can better legitimate any postulate than the insights gained by it? Besides, what can further justify the validity of this approach is the fact that the postulation of a "disunified unity" in the text is in fact no more than the application of Pope's own criterion for genuine criticism: the "[s]urvey the Whole" (236) principle. ${ }^{8}$

4. Cf. Jennifer Snead, "No exit? Recent Publications on Pope," in Eighteenth-Century Studies 38.2 (2005), p. 349.

5. Snead, p. 350 .

6. A term used by Patricia Meyer Spacks, author of the most comprehensive and insightful interpretation of the Essay previous to Smallwood's. See Patricia Meyer Spacks, "Wit Governing Wit," in An Argument of Images: The Poetry of Alexander Pope (Cambridge, Massachusetts: Harvard University Press, 1971), p. 19.

7. Smallwood, p. 151.

8. All parenthesized references are to this edition: Alexander Pope, Pastoral Poetry and An Essay on Criticism: The Twickenham Edition of the Poems of Alexander Pope, Vol. I, ed. E. Audra and Aubrey Williams (London: Methuen, 1961). 


\section{JÁNOS BARCSÁK}

What Pope apparently means by this principle is that one should allow the object of critical study to have its own singular order and organization and not impose one's own prejudices and specific requirements on it. Individual parts of the piece under critical scrutiny must be judged in terms of a unified whole which the critic must postulate. To put it in more modern terms, one must allow the object of study to be other and to propose its own terms in which it wants to come to us.

This approach to the poem, therefore, necessarily (and I think quite legitimately) postulates a "unified whole" which underlies the text. The search for this "disunified unity," however, is by no means a simple process: it entails certain methodological requirements. It is quite clear, first of all, that such a unity is not to be found in the discursive content of the text alone: one must also consider how "the poetry" interacts with the propositions of the text. In other words, one must see how formal elements (rhythms, rhymes) and especially the use of imagery demonstrate the meaning of the statements and how they also qualify, problematize and enrich the meaning. 9 This approach, however, will still not yield the "unified vision" which we seek. As Smallwood puts it "it is one thing to say that the Essay on Criticism uses imagery, another to say where all the imagery points." ${ }^{10}$ Secondly, therefore, one must supplement the study of the local effects of "the poetry" with a study of how all (or at least most of) the images stem from and embody the same unified vision. Thirdly, one must keep in mind throughout this whole process that the unified vision which one seeks can never be exactly identified or abstracted from its particular manifestation in the text. Such a clear identification would be a reduction of the alterity of the work and would violate the "[s]urvey the Whole" principle. We postulate the whole precisely in order to avoid the danger of finding it in any particular formulation which is not the entirety of the text itself.

No matter how carefully one observes this last methodological precaution, however, one can still not eschew one's ideological positionality. Inevitably, one brings to the text what one discovers in it. It is thus that Smallwood finds in the Essay a "definition" of criticism and it is thus that I will propose my own reading, too. In particular, what I will propose as a unifying vision in the poem is a genuine experience of creativity. I will argue, in other words, that what organizes the heterogeneous and often seemingly paradoxical discursive content and the poetry (the similes, metaphors, imagery) of the text into a "disunified unity" is an attempt to account for this unaccountable but also undeniable experience. I will base my argument on an analogy that I think can be established between Pope's poem and

9. This method of analysis has been beautifully outlined and employed in Patricia Meyer Spacks's An Argument of Images.

10. Smallwood, p. 152. 
Derek Attridge's ideas about creativity ${ }^{11}$ in art and especially literature. I choose Attridge's theory as a starting point because I think that it is perhaps the most lucid and systematic treatment of this aspect of the issue of creativity and, besides, it is clearly based - just as Pope's Essay is - on lived and felt experience. ${ }^{12}$

This comparison might at first seem to be striking, since no two things seem further apart than Attridge's tolerant and inclusive approach to the experience of creativity and Pope's strict, judgmental, rule-governed neoclassical attitude. ${ }^{13}$ I will argue, however, that in spite of these apparent differences Pope ultimately speaks from the same ethical position as Attridge. Even the neoclassical rules, which seem entirely antithetical to Attridge's conception of creativity, ${ }^{14}$ are treated by Pope to strengthen this ethical position. In fact, I will argue, Pope's discussion of the rules can be seen as a useful extension of Attridge's ethical position and might thus be seen as vitally relevant in our 21st century discourse on literature.

\section{Nature as the Other}

For Attridge - as for Derrida, on whose essay "Psyche: Invention of the Other"15 he relies heavily - creativity is always the invention of the other in the double sense of this phrase: firstly, creativity is the invention of the other in the sense that it consists in inventing the other, bringing it into the discourse of the same as the wholly new; but, secondly, if creativity is successful, the credit for this success always goes to the other, and thus creativity is the invention of the other also in the sense that the wholly new is invented by the other. What this double meaning of the phrase implies is that although in the experience of creativity we must always aim at creating the other, bringing it into the same, the actual appearance of the other is never something that we can predict, calculate with, or control in any way. What I think fulfils this function of the other in Pope's discussion of creativity in the Essay on Criticism is Nature.

11. The two works that I will primarily rely on are Derek Attridge, "Innovation, Literature, Ethics: Relating to the Other," PMLA 114 (January 1999) 20-31; and Derek Attridge, The Singularity of Literature (London and New York: Routledge, 2004).

12. For a different approach to the connection between modern accounts of creativity and Pope's work see Netta Murray Goldsmith, Alexander Pope: The Evolution of a Poet (New York: Ashgate, 2002).

13. Attridge's examples indeed often refer to neoclassical expectations and norms as the representation of the same which the coming of the other breaks down (e.g. Attridge, Singularity, pp. 31, 39).

14. Attridge even declares that "literature rests on a certain inaccessibility to rules" (Attridge, Singularity, p. 13).

15. Jacques Derrida, "Psyche: Invention of the Other," in Psyche: Inventions of the Other (Stanford: Stanford University Press, 2007), 1-47. 


\section{JÁNOS BARCSÁK}

This analogy between modern discussions of alterity and Pope's concept of Nature is of course by no means self-explanatory. Although it is true that the success of any work of art for Pope is dependent on the presence of Nature in the work, the terms in which he describes this concept seem to be directly opposed to the way the other is presented in modern theory. Attridge, for example, conceives of the other as something that is emphatically not an entity, but something that "beckons or commands from the fringes of my mental sphere," it is "other because it has not yet come into being." ${ }^{16}$ For Pope, by contrast, Nature is apparently something that is given once and for all: it is a finished entity which exists in the form of a fixed and finite set of rules. This view is clearly expressed for example in the passage where Pope, after the introductory part of the poem, gives his first and most general advice to the poets and critics establishing the ultimate significance of Nature for poetry:

First follow NATURE, and your Judgment frame

By her just Standard, which is still the same:

Unerring Nature, still divinely bright,

One clear, unchang'd, and Universal Light,

Life, Force, and Beauty, must to all impart,

At once the Source, and End, and Test of Art.

Nature appears here as a never changing, omnipresent standard which has once and for all "fix'd the Limits fit" (52). The snappy brevity of this statement emphasizes arbitrary power and authoritative limitation - characteristics that are not usually associated with the other. However, if we take it seriously that the other should not be thought of primarily as an entity and it exists only in my relating to it, ${ }^{17}$ then we cannot fail to observe that the way Attridge describes the creative relation to the other is remarkably similar to what Pope says about how the poet (and critic) should relate to Nature. The relation to the other, as we have learnt from modern theory, must first of all be a relation that lets the other be other; that is, that does not attempt to accommodate or appropriate the other in the same. I can have no demands on the other, while the other makes unconditional demands on me. I must cede control to the other entirely, because without this unconditional surrender it will not come. And indeed this is exactly how Pope describes the way the poet (or critic) must relate to Nature. Nature can in no way be influenced by us, we cannot add anything to it, we cannot take away anything from it: we can make no demands on it whatsoever. On the other hand, Nature demands unconditional

16. Attridge, "Innovation, Literature, Ethics," p. 23.

17. Attridge, "Innovation, Literature, Ethics," p. 22. 
surrender, for it is "At once the Source, and End, and Test of Art" (73): unless it comes, creativity cannot take place, but it will only come if we unconditionally accept its own terms.

In the way the poet or critic must relate to it, therefore, Nature functions in Pope's Essay similarly to the other in modern accounts of creativity. ${ }^{18}$ This similarity is further confirmed if we examine the metaphorical devices that Pope uses to convey his ideas about the significance of Nature in poetry. In the passage quoted above the image that expresses the unconditional demand of Nature as the other is the image of light. Light is certainly one of the most prominent images in the poem ${ }^{19}$ and its association with Nature in this early and emphatic passage establishes its importance even more firmly. More particularly, what we can observe in these lines is the metaphorical identification of Nature with the source of all light, the sun. Nature, like the unchanging sun, shines on us from above, it gives life, force and beauty to everything: it is the ultimate given. Whether we know about it or not, whether we make use of it or not, the simple and universal order of Nature is always there like the unchanging sun.

This is so far not unexpected at all, since this use of the sun image can be easily accounted for from the characteristic "neo-classical" concept of Nature. Knowing how the Augustans thought of Nature, it is quite appropriate and according to our expectations that the sun should be associated with it. ${ }^{20}$ And it is indeed the universal and unchangeable quality of something given that most of the major recurrences of the image of the sun confirm in the poem..$^{21}$ Curiously enough, however, there is

18. My treatment of Nature in terms of the Attridgean conception of the other here and elsewhere in this paper inevitably overlooks a crucial element in Attridge's theory: his focus on the culture-dependent quality of the other. Indeed one of the most insightful and inspiring elements in Attridge's theory is his insistence that the other is in fact always just gaps, contradictions, tensions in the tissue of the same. And if this is so, Attridge argues, then the other is always dependent on a particular cultural situation, on a particular arrangement of the same in which those gaps, contradictions, tensions occur (cf. Attridge, Singularity, p. 25). It is always only to this particular cultural situation that the other is other (cf. Attridge, Singularity, p. 29). What is more, the other is also dependent in a similar way on the particular ideoculture of the individual subjectivity which experiences it either in creation or in reading. (cf. Attridge, Singularity, pp. $67,78)$ This aspect is clearly neglected in Pope's treatment of the concept of nature. However, I would still maintain that this is only a shift in emphasis rather than a substantial difference. In their description of the experience of encountering and relating to the other, the essential structural similarity between Pope and Attridge remains (see also note 49 below).

19. Cf. Spacks, pp. 32-4.

20. On the neo-classical view of nature see for example Audra and Williams, "Introduction" to An Essay on Criticism in Pope, Pastoral Poetry, pp. 219-22.

21. In lines 399-405 the sun stands for the universal presence of talent and inspiration among the nations and ages, regardless of the particular time or place; and in the passage 


\section{JÁNOS BARCSÁK}

an exception to this rule. In an emphatic passage on the concept of "expression" the sun image is used in a very different context:

But true expression, like th' unchanging sun,

Clears, and improves whate'er it shines upon,

It gilds all objects, but it alters none.

If we follow the "one image - one meaning" principle in our interpretation of the poem, then these passages clearly contradict each other. The light of the sun is once the universal order of Nature itself and then it is the expression of that order; and the universal order, which was the light itself in the first passage, seems to be the things as they are in the second, it seems to be what the light shines on.

This self-contradiction could of course be glossed over as just one of the many inconsistencies in Pope's Essay that almost all commentators have dutifully noted since John Dennis's famous attack on the poem. ${ }^{22}$ However, paradox can also be looked at as a tool for producing meaning in poetry, and in the light of what has been said about the analogy between Pope's poem and modern theories of creativity this particular paradox (as well as several other similar ones) can very well be accounted for as a representation of the experience of the coming of the other. Let us assume, therefore, that the paradox that the text establishes here is what Pope means to say. If the light of the sun is the universal order of the world and also the perfect expression of that order, if Nature is the light itself and at the same time it is what the light shines on and makes visible, then we can assume that Pope means to say that these things are (or should be) identical. The things as they are and the light in which they become visible are - at least ideally - one and the same thing, which is to say that the light in which things become manifest to us in fact makes the things the way they are but without changing them.

This paradoxical situation is indeed very similar to what modern theories of alterity say about the experience of creativity. Creativity occurs, according to these theories, if the other comes into the same. The other is prior to, more original than, the same; as Jacques Derrida puts it, "the other will have spoken first"; 23 nevertheless, the other can only become manifest, and thus can only come into being within

where the sunlight is associated with Dryden and Homer (466-73), its function is to emphasise the universal and invincible power of "sense" and true "merit."

22. John Dennis, "Reflections Critical and Satyrical, upon a Late Rhapsody, Call'd, An Essay upon Criticism," in The Critical Works of John Dennis, ed. Edward Niles Hooker (Baltimore: The Johns Hopkins Press, 1939), 396-419.

23. Jacques Derrida, "Mnemosyne," in Memoires: for Paul de Man (New York: Columbia University Press, 1986), p. 37. 
the same, within a medium which is essentially different from it. ${ }^{24}$ And it is precisely this double nature of the single experience of creativity that Pope's paradoxical use of the sun image demonstrates. The light of the sun is both Nature (the other) as it in itself is and true expression, that is, - to use Attridge's terminology - the same refashioned according to the demands of the other, since this is the only way in which the other can exist.

Nature and true expression, the other and the particular rearrangement of the same according to the demands of the other, are therefore united in the experience of creativity and whenever a work of art is created this union actually takes place. Thus all works of art that are innovative in Attridge's sense, ${ }^{25}$ that is, that engender a creative response, bear testimony to the existence of this paradoxical union. For Pope it is the classics that primarily testify to this paradoxical union. It is no wonder, therefore, that in his discussion of the significance of the classics he repeats the same paradox that we have observed in his use of the image of the sun. As it was noted already by John Dennis, ${ }^{26}$ Pope creates a paradox when in line 135 of the Essay he says that "Nature and Homer were ... the same," while in lines 88-9 he claims that they are two different things when he says that the "rules" of the classics (which can here be identified with Homer) "are Nature still, but Nature Methodiz'd." This self-contradiction clearly exhibits the same pattern as the paradox hidden in the apparently inconsistent use of the light metaphor. In Homer, the text asserts, Nature and its expression, the other in its otherness and the way it becomes manifest to us in poetry, are one and the same thing, they are inseparable in the achievement of the great classical poet. Nevertheless, this ideal unity - as we have also seen in the use of the sun image - exists only as a union of two distinct and irreconcilable elements: Nature as it is in its unchanged and unchangeable order (the other), and its expression. The first of these elements is a universal given: it is totally impervious to any human attempt to alter it, damage it or grasp it (in the sense of extending control over it); the latter is the result of human action.

I believe that this connection between the other and its manifestation in the material of the same forms the basis of the major metaphorical constructs of Pope's poem. It underlies several of the master metaphors in the text, including for example the soul/body, the Nature (or thought)/dress, and the sketch/colour oppositions. In each of these metaphorical oppositions the former element represents the unchangeable, uncontrollable other, while the latter is its manifestation in the

24. Cf. Attridge ("Innovation, Literature, Ethics," p. 21): "when I experience alterity, I experience not the other as such (how could I?) but the remolding of the self that brings the other into being as, necessarily, no longer entirely other."

25. Attridge, "Innovation, Literature, Ethics," p. 22.

26. Dennis, p. 401. 
same; the former is intangible, invisible but, if it gives itself, it invests visible matter with form, while the latter is tangible, visible but in itself formless; the former is unaffected by any outside force and thus the same can have no power over it, while the latter can be brought under human control but is also fallible, corruptible. Ideally, as for example in the classics, these two are like the recto and verso of the same sheet of paper, but because of its origin in the same, the second element is corruptible; it is exposed to human weaknesses.

As Pope conceives of the former element in each of these oppositions in terms of the God-given order of Nature which is beyond the reach of conscious action, it is inevitable that he focuses his attention on the latter element, the one which can be brought under human control and which, therefore, is fallible. His conception of the other in terms of a divine given leads thus to a crucial difference between the Essay and modern discussions of the experience of the coming of the other. Whereas modern interpretations of this experience, like for example Attridge's, tend to focus on how the other disrupts and breaks down the same, Pope pays attention primarily to how the same prevents the other from coming, how human efforts to achieve the ideal unity of Nature and its expression tend to fall short of this ideal. This difference, however, is only a difference in the direction of approach, which leaves the fundamental structure of the experience intact. We can, therefore, read Pope's treatment of how the same tends to get in the way of the other as a useful extension of modern theories of creativity. What we can learn from Pope's Essay in particular is that the human error which prevents divine Nature from coming is a systematic error; that the various ways in which the same suppresses the other converge on the same recurring mechanism. This systematic error or mechanism is termed in the Essay "pride." If we want to understand Pope's treatment of creativity, therefore, it is essential that we first focus on how Pope describes the mechanism of pride.

\section{The mechanism of pride: the cloud and a little learning}

Since Pope grounds his discussion of poetry and criticism on the heavily loaded word pride, the terminology he deploys is inevitably that of the moral and the pragmatic - considerations that are quite alien to Attridge and to modern accounts of the literary in general. However, I would like to argue that what informs Pope's moral and pragmatic considerations is always a commitment to the experience of creativity and invention; it is always the responsibility for the other. I will try to show, therefore, that what appears to be pragmatic and moralizing in the Essay is in fact always the expression of Pope's ethical commitment. Thus when Pope discusses pride as the ultimate moral error and as the main source of all human failure, his 
moral indignation is in fact raised by the lack of sufficient commitment to the other and his pragmatic advice is directed at removing the same which always tends to get in the way of the other.

For Pope, as we have seen, the other (Nature) is like the unchanging sun which comes to us of its own accord, which gives itself whether we ask for it or not, whether we accept it or not, whether we know about it or not. Yet it is an undeniable fact that most of the time this light does not reach us; more often than not the other is prevented from coming into the same. The fact that it is possible for Nature (the other) to inform a human-made artefact is attested to by the classics, but it is undeniable that in most cases we fall short of this perfect union of the same and the other. The reason for this failure cannot be the other; for, according to Pope, it always gives itself like the light of the sun. The reason why this light usually does not reach us is rather that there is always something that stands between us and the light: a cloud that is always rising to obscure our sight and that we must constantly struggle to get rid of. This cloud is identified in the poem as pride:

Of all the Causes which conspire to blind Man's erring Judgment, and misguide the Mind What the weak Head with strongest Byass rules, Is Pride, the never-failing Vice of Fools.

Pride, where Wit fails, steps in to our Defence,

And fills up all the mighty Void of Sense!

If once right Reason drives that Cloud away,

Truth breaks upon us with resistless Day. . .

(201-12)

The imagery Pope uses here implies a subtle description of the mechanism of pride. Like the cloud, human pride seems to rise without any provocation, without requiring any effort, just by the sheer force of inertia. It flows into, fills any void that it finds - not because it has any purpose or with an intention of doing harm, but because it is an inevitable tendency that gas fills out an empty space and that vapour rises when the sun shines. ${ }^{27}$ To get rid of pride, however, we must make an effort; only if the cloud is consciously driven away can we have access to the light of the sun. Pride, in other words, works on the principle of entropy: it always obstructs and hinders, unless we invest great energies to get rid of it.

This description of the mechanism of pride implies a distinct ethical attitude; an attitude which is perhaps worth elaborating on even if in this passage it is only implicit, as it seems to underlie everything that Pope says about the task of the poet

27. This latter simile is introduced only in lines $470-3$ but in a very similar context. 
and of the critic later on in the Essay. What this imagery implies is that the greatest human achievement is getting rid of one's own pride, the inertia of the same, and ultimately getting rid of that which is always at home in the same: the self. The truth which is simple and clear as the light of day (212) is given by the other, we cannot alter it, we cannot have any impact on it and least of all can we make it. All we can achieve is simply to commit ourselves fully to this truth; that is, to assume full responsibility for the other and for what comes from the other. And what this involves is ultimately driving the cloud of pride away, getting rid of the inertia of the same in order to clear our vision, and allow the gift of the other to come to us. Success, in other words, is the elimination of the self. When we are thus successful, however, the success is in fact not ours. All we achieve is only to drive the cloud away so that the sun can shine in, but the warmth, the clarity, the pure light is not ours; it always comes from the other.

It is a natural tendency, however, and this is also implied in the word "success," to think that when success is achieved, it belongs to the self. The inevitable tendency of the self is to accommodate the gift of the other in the same. However, as soon as we assume that the success is ours, we have fallen into the trap of pride and have blurred our own vision. To think that any success is ours is in fact failure itself. Besides, it is quite ludicrous, too, as in this way we only do harm to ourselves. When we raise the clouds of pride we do not offend against the light. The sun always shines, even above the thickest clouds. We just make it impossible for ourselves to see this light clearly.

As I have said, this mechanism of pride and the ethical commitment that it necessitates can be said to underlie everything that Pope says about the tasks of poetry and of criticism in the poem. His moralizing/pragmatic approach, therefore, derives from and thus becomes an expression of the responsibility for the other. Besides, this fundamental ethical commitment can also account for the conspicuous negativity of Pope's argument. Indeed it is very difficult to find any positive advice in the poem as to the poet's or the critic's task. Pope seems to say in the Essay very little about what a poet or a critic should do, while he is eloquent on what they should not do. In the light of the description of the mechanism of pride and the ethical position that is connected to it, it becomes clear why this is necessarily so. The task is in fact essentially a negative one: poets and critics (as well as any human being in general) must struggle against the force of inertia coming from the same which inevitably hinders all our efforts. The best way for Pope to give pragmatic advice, therefore, is to draw our attention to some particular manifestations of pride in poetry and criticism that typically plague these human activities and that we ought to get rid of.

The first and most general of the hindrances that poets and critics must struggle against is "a little learning," which can even be identified as pride in poetry and in criticism, as it seems to be the source of all errors that poets and critics are prone to. 
A little learning is a dangerous thing;

Drink deep, or taste not the Pierian spring:

There shallow draughts intoxicate the brain,

And drinking largely sobers us again.

It is, I think, no wonder that these lines have acquired proverbial status in English. The passage registers an experience that we have all had with such clarity, conciseness and wit that this really comes up to Pope's own standard of true wit: "What oft was Thought, but ne'er so well Exprest" (298). The intoxication with a new idea, with a new field of knowledge is a common human experience (a month after you have started taking karate lessons, for example, you take every opportunity to pick a fight because you believe that you can beat anyone). Besides spotting and wittily representing something characteristically human, however, in these couplets Pope also manages to convey a sense of the mechanism of pride which I have tried to describe above. The little learning is acquired without any effort; we are driven to acquire it by our natural curiosity and also by the prospect of inflating our own self by the power this knowledge might give us. Of course, as Pope points out, the best cure for such intoxication by a little learning is more learning (to stick with my previous example: learn more about martial arts and you choose to run away next time when a conflict might develop into a fight). But to acquire more learning we must already invest energy, which is especially difficult because the profit of this investment promises to be only the discovery of our own littleness, our insignificance. The supreme effort required and the disappointment that inevitably results from more learning is beautifully expressed in the passage that follows hard upon the one quoted above and that deploys the famous simile which Dr Johnson judged to be "the best that English poetry can show": 28

Fir'd at first Sight with what the Muse imparts, In fearless Youth we tempt the Heights of Arts, While from the bounded Level of our Mind, Short Views we take, nor see the Lengths behind, But more advanc'd, behold with strange Surprise New, distant Scenes of endless Science rise! So pleas'd at first, the towering Alps we try, Mount o'er the Vales, and seem to tread the Sky; Th' Eternal Snows appear already past,

And the first Clouds and Mountains seem the last:

28. Samuel Johnson, "The Life of Pope" in Alexander Pope: A Critical Anthology, ed. F. W. Bateson and N. A. Joukovsky (Harmondsworth: Penguin, 1971), p. 138. 
JÁNOS BARCSÁK

But those attain'd, we tremble to survey

The growing Labours of the lengthen'd Way,

Th' increasing Prospect tires our wandering Eyes,

Hills peep o'er Hills, and Alps on Alps arise!

$(219-32)$

\section{What Poetry is not}

After his general discussion of the dangers of a "little learning" in poetry and criticism, Pope levels his attack at more particular excesses, more particular manifestations of pride in critical judgment. More specifically, he discusses three typical poetic errors: the excessive use of conceit, the exaggerated fondness for style and eloquence, and the prejudice for smooth rhythms. Pope introduces these three errors in poetry as three ways in which poets tend to favour only one part of the poetic task and thus to forget about the whole. However, if we examine these three cases, and especially if we study the metaphors and similes that Pope uses in presenting them, we cannot fail to notice that what underlies each of them is precisely the mechanism of pride discussed above.

Each of these errors, then, is a particular instance of the general way in which the same obscures the other. In each case the same, that which should be a "true expression" of Nature (the other), assumes priority and thus prevents the other from coming into it. In each case the poetic medium (language, metre, wit, the use of metaphor), whose raison d'être consists only in expressing, making visible, giving way to, the other, draws attention to itself and thus blots out the light of Nature (the other) which should shine through it. And in each case this happens because of the sluggishness, the inertia of the poetic medium, that entropic movement of the same which, like a cloud, always blurs our sight and which Pope terms pride.

In the first instance, the discussion of conceit, Pope uses the analogy of painting to represent this entropic movement.

Some to Conceit alone their Taste confine, And glitt'ring Thoughts struck out at ev'ry Line;

Pleased with a Work where nothing's just or fit;

One glaring Chaos and wild Heap of Wit:

Poets like Painters, thus, unskill'd to trace

The naked Nature and the living Grace,

With Gold and Jewels cover ev'ry Part,

And hide with Ornaments their Want of Art.

I think it is not difficult to see the mechanism of pride in operation here. The excessive use of witty similes or conceits in poetry is compared to the practice of bad 
painters who try to draw the viewer's attention away from the lack of the true light of Nature in their painting by the abundant use of glaring colours. In other words, Pope juxtaposes here the difficult but truly creative activity of assuming responsibility for the other (tracing "the naked Nature") with the cheap sensuous effect of using a lot of glaring colours. The latter procedure, just as the use of too much wit in poetry, is merely a manifestation of the inertia of the same, it is an easy way to impress an audience, but its real effect is in fact to cause a kind of blindness. Like pride in general, the use of too much wit in poetry or too much colour in painting prevents the true light of Nature from coming to us. The image of the cloud is replaced here by the image of the blinding light of glaring colours but the effect is the same: we become unable to see the light, the gift of the other. ${ }^{29}$

This point is illuminated further in the next section of the poem where Pope attacks the excessive emphasis that bad poets sometimes lay on language, that is to say, on style and eloquence.

Others for Language all their Care express, And value Books, as Women Men, for Dress. . .

The dress metaphor is evoked here and receives its most extensive treatment a few lines further on in this passage. I will examine Pope's use of this metaphor at some length in the next section. However, it is proper to observe at this point that there is a conspicuous similarity between the painting analogy and this metaphor, which, I think, is occasioned by the fact that the mechanism of pride underlies both. Dress, thus, appears here as a representation of the same (the poetic medium, language) whose proper function - as Pope explains elsewhere (297; 318-23) - is to show its wearer's features to advantage. It fulfils its role if it makes the man (Nature, the other) visible. However, in the absence of Nature, the dress inevitably tends to draw

29. A similar situation is outlined in Pope's other use of the painting analogy in a previous passage where he develops a contrast between judgement and false learning:

Yet if we look more closely, we shall find

Most have the Seeds of Judgment in their Mind;

Nature affords at least a glimm'ring Light;

The Lines, tho' touch'd but faintly, are drawn right.

But as the slightest Sketch, if justly trac'd,

Is by ill Colouring but the more disgrac'd,

So by false Learning is good Sense defac'd. . (19-25)

Judgment (or at least the seeds of it) is associated here with Nature, it is a natural given. This natural given is analogous with the sketch, the design in painting, which the inappropriate use of colour, associated here with false learning, spoils in much the same way as too much wit spoils "the naked nature" in the passage on conceit. 
JÁNOS BARCSÁK

attention to itself and thus to blind the observer with its excessive finery. A coxcomb (whose image is clearly implied in the use of the dress metaphor above) is tempted to such excesses because this is an easy way to create a dazzling effect. However, like the coxcombs of Restoration comedy, the wearers of such excessively decorated clothes use their dress only to cover up for their inner insufficiency, for the lack of Nature within. Similarly, if poets are excessively eloquent, they in fact only display the lack of Nature, the absence of the other in their work. The style and eloquence, which belong to the same, only serve for such poets as a dazzling effect to blur the sight of the beholder.

The next section in the poem presents yet another manifestation of the working of pride. In this passage Pope attacks the attraction of weak poets to smooth, rocking, but therefore monotonous rhythms, to what is referred to here as numbers.

But most by Numbers judge a Poet's Song,

And smooth or rough, with them, is right or wrong...

This poetic error, it becomes clear, is once again a falling away from the ideal unity of the same and the other, of expression and Nature. This ideal unity is represented here in the requirement that

'Tis not enough no Harshness gives Offence, The Sound must seem an Eccho to the Sense.

(364-5)

"Sound" and "Sense" are of course on a different level than Nature and expression, but the pattern is recognizably the same: sound, if we give way to our inclinations, gets in the way of sense and obscures what it should make visible.

\section{What, then, is poetry?}

In these three passages (on conceit, on "language" and on "numbers") Pope discusses, as is his usual way in the Essay, what poetry is not. However, from these primarily negative descriptions we can also gain some positive insight into the nature of true poetry. If the greatest poetic error is to let the poetic medium (the same) obscure the pure light of Nature (the other), then the poetic task, positively outlined, is to get rid of all that is contingent in the poetic medium, to purify it to the point where it becomes entirely transparent and thus lets the light of Nature shine through it.

This task, however, is a doubly paradoxical one. It is paradoxical, first of all, because it is a task of self-annihilation. The poetic medium (be it language, wit or meter) fulfils its function only when it ceases to be itself and exists only by virtue of something more valuable beyond it: Nature (the other). However, as we could see 
above, the poetic medium is also essentially necessary, because, and this is the second paradox, it is only through this medium (the same) that the other can become manifest. On the one hand, then, the poetic medium is something that must be conquered, that we must struggle against and ultimately eliminate; on the other hand, however, it is only in this particular struggle, it is only in the face of the essential sluggishness and inertia of the same, that creativity can take place.

This paradoxical situation can I think very well be accounted for by what Derek Attridge describes as the act/event structure of creativity. "Creation, then," Attridge explains,

is both an act and an event, both something that is done and something that happens. Since there is no recipe, no program, for creation (this is part of what we mean by creation), it cannot be purely a willed act; but since creation requires preparation and labor, it cannot be purely an event. ${ }^{30}$

Indeed for Pope, as we have seen, the appearance of "the naked Nature" in successful poetry is not something that can be actively forced or controlled; it is rather the event when "[t]ruth breaks upon us with resistless day" (212) or, as Attridge puts it, 31 "the irruption of the other" - an event which we can only passively receive. However, this miraculous event can only come to pass by and in the active manipulation of the poetic medium; it can only exist as an act, as "the active reshaping of existing configurations," 32 as the active manipulation of the same. When discussing the poetic task, therefore, Pope in fact talks about how the active manipulation of the poetic medium can make it possible that the event of creativity take place. Hence the paradoxes: the active manipulation of the same must always be the act of completely "surrendering one's goals and desires in deference to the other's," 33 that is to say, annihilating the same; but at the same time the event of the coming of the other can only take place by and in the act of manipulating the same (the poetic medium) and thus the same and the conscious activity of the poet in his medium are also indispensable in the act/event of creativity.

What ultimately underlies Pope's discussion of the paradoxical task of poetry is, therefore, the experience of creativity whose structure is easily recognizable in the three passages discussed in the previous section. In the passage on conceit (28996), for example, Pope uses the painting analogy to this effect. When we look at the painting, he suggests, what we should see is just "[t]he naked Nature and the living Grace," not the colour. However, he does not say that there is no need for colour. In

30. Attridge, "Innovation, Literature, Ethics," p. 22. Cf. also Attridge, Singularity, p. 43.

31. Attridge, "Innovation, Literature, Ethics," p. 22.

32. Attridge, "Innovation, Literature, Ethics," p. 21.

33. Attridge, "Innovation, Literature, Ethics," p. 27 


\section{JÁNOS BARCSÁK}

fact it seems that colour is referred to as the necessary medium of painting, but the painter's task is to make this medium entirely transparent, to let "the naked Nature" shine through it. The use of colour is not in itself a fault, in fact it is a necessity, it is as necessary - to anticipate a metaphor that I will discuss later - as a physical body is necessary for a soul to become manifest. The fault is when one lets the colour dominate in the painting and thus obscure "the naked Nature" instead of letting it come forth, instead of manifesting it as it demands to be manifested. Similarly, what Pope seems to say here about wit in poetry (by which at this point he clearly means the use of simile and metaphor) is not that it is in itself a fault. On the contrary, on the analogy of colour in painting it seems that wit is a necessary medium, it is the medium in which alone poetry can operate. What Pope criticizes is the use of false wit, as in conceits, which tends to obscure the light of "[t]he naked Nature and the living Grace." "True Wit," as opposed to this,

is Nature to Advantage drest,

What oft was Thought, but ne'er so well Exprest, Something, whose Truth convinc'd at Sight we find, That gives us back the Image of our Mind...

This passage is a central one in the poem and has therefore deservedly attracted a great deal of critical attention. However, much of the critical commentary on these lines has been directed at pointing out the inaccuracy of Pope's statements. What I think the commentators tend to overlook is that the centrality of this passage in the conceptual framework of the Essay is due to the fact that it is perhaps the most explicit statement in the poem of the paradoxical structure of the experience of creativity. If we examine these lines in the light of what has been said about the act/event duality, it turns out that what has seemed to some commentators to be a mere paradox, or at least an inaccuracy, is in fact constitutive of Pope's creative account of the creative experience.

What critics have traditionally found fault with in this passage is the metaphorical identification of poetic expression with dress; an identification which is further confirmed in another famous passage on "language":

Expression is the Dress of Thought, and still

Appears more decent, as more suitable;

A vile Conceit in pompous Words exprest, Is like a Clown in regal Purple drest. . .

In a letter to Pope Aaron Hill objected to the "Nature to Advantage drest" formula and went on to criticize the second passage suggesting that "the idea must have been shape (not dress) of thought; dress, however an ornament, being a concealment, or 
covering; whereas expression is manifestation and exposure." 34 Similarly, Dr Johnson was dissatisfied with the "What oft was Thought, but ne'er so well Exprest" phrasing, indicating that it merely meant the verbal elaboration of an accepted commonplace. ${ }^{35}$ Following his lead Norman Callan suggests that if we altered this line to "What oft was thought, but ne'er so well thought" we would probably come nearer to an accurate description of Pope's actual procedure. These criticisms are of course valuable in each case as they help to make interesting critical points clear. In the light of the two passages quoted above, however, we just cannot ignore the fact that for Pope to express is to dress ${ }^{36}$ and that the dress, the expression, is not merely an outer cover but an essential constituent of the thought that it exposes.

I think that what we can thus recognize in Pope's insistence on the metaphorical identification of expression and dress is precisely the paradoxical act/event structure of creativity. Pope insists that the experience of creativity can only be accounted for as the coincidence of two entirely incompatible notions: on one side we find the person who wears the dress (Nature, thought, the other), while on the other side there is the dress (expression, the poetic medium, the same). Of these two the first is a given: we cannot change it or influence it in any way. The latter, by contrast, can be tailored, manipulated, consciously controlled. The two are in themselves entirely incompatible, the same being defined as that which gets in the way of the other, the poetic medium as that which tends to obscure Nature, and the dress as that which covers and conceals. In the event of creativity, however, these essentially opposing sides suddenly coincide: the same becomes a container of the other, Nature shines through the poetic medium and the well-tailored dress shows off its wearer's features to the best advantage. When this event takes place, it can only be accounted for as the coming of the other: we become aware of "Something, whose Truth convinc'd at Sight we find," we are given immediate (unmediated) access to Nature (the other). Therefore, as we could see in what I have called the first paradox

34. Quoted in Leopold Damrosch, Jr., The Imaginative World of Alexander Pope (Berkeley: University of California Press, 1987), p. 221.

35. In Peculiar Language, Derek Attridge also agrees that Pope is proposing here "the most pithy and the most familiar statement of the commonplace" (Derek Attridge, Peculiar Language: Literature as Difference from the Renaissance to James Joyce [London: Routledge, 2004], p. 49). For him, however, this is not a shortcoming in Pope but a solution to the problems raised by the supplementary relation of art to nature (see below).

36. It is, I think, also significant that in both these passages Pope rhymes dress with express. In the light of W. K. Wimsatt's analyses of Pope's use of rhyme, we cannot but assume that he rhymes these words because he wants to indicate the essential connection between the two notions. Cf. W. K. Wimsatt, "One Relation of Rhyme to Reason," in The Verbal Icon (London: Methuen, 1954), p. 161. 


\section{JÁNOS BARCSÁK}

of creativity, the same seems to fulfil its function in self-annihilation: the good dress disappears as it makes its wearer visible and, similarly, good poetry ("true wit") becomes invisible as it exposes the naked Nature. However, what comes thus, and this is the second paradox, can only come by virtue of the same: without the dress its wearer's beauty could never become manifest, without the poetry Nature could never be exposed. It is only by virtue of what is in itself opposed to it that the other can come to light. Only by covering/concealing can the dress make visible and, similarly, only by being (and remaining) a medium can poetry provide unmediated access to Nature. 37

To understand the experience of creativity, therefore, it is essentially important to keep these two notions apart: poetic expression is only dress, it cannot account for what comes through and in it; however, that which comes can only come (and therefore only exists) through and in the self-annihilation (responsibility) of the dress of poetic expression. It is this situation that can provide an answer to Dr. Johnson's objection, too. When Pope insists that what must be made visible in poetry is "what oft was Thought," he by no means implies, as Johnson believed he did, the received commonplace. What he implies is rather what Attridge describes as the tangled temporality and unusual causality of the experience of creativity. ${ }^{38}$ What comes in this experience is "[s]omething, whose Truth convinc'd at Sight we find," something that "breaks upon us" with the evidence of that which we have always already known and thought. As such it necessarily precedes in its being the experience in which it comes to us and is perceived as the cause of this experience. However, this does not imply that what we become aware of in this way is a received commonplace. Far from it; this realization of what we have always thought can in fact only take place within that singular encounter with a work of art. Without the experience, without the particular dress of poetic expression, I would never have been able to realize that I have always known this truth. My encounter with a particular poetic expression, therefore, causes me to realize that truth and thus it chronologically precedes the truth, too. What Attridge says about the creative process can thus be easily adapted to what Pope says in this passage about the encounter with a truly creative work:

37. In Peculiar Language Derek Attridge describes a similar dynamic in the relation between nature and art in terms of the Derridean concept of supplementarity (Peculiar Language, pp. 17-45). Taking Puttenham's Arte of English Poesie as a starting point and guiding thread Attridge shows here in a brilliant and many-faceted analysis how the supplementary relation between art and nature is formulated in the thought of the renaissance and how it keeps determining the inquiry into the peculiar language of literature in later ages, including Pope's age, too (on Pope see Peculiar Language, pp. 46-49).

38. Attridge, "Innovation, Literature, Ethics," p. 28. 
As has often been remarked, the sense of finding the appropriate word in a poetic line or articulating the next stage of an argument is that of achieving what one was seeking and would be accurately expressed not by "At last, I’ve made something new!" but rather by "At last I've got it right!" or even "At last I've got it!" . . what is foremost in the creative mind is the issue neither of originality nor of communication; it is the demand that justice be done to thoughts that have not yet even been formulated as thoughts. 39

Similarly, what Pope seems to imply in the "What oft was Thought, but ne'er so well Exprest" formula is that the encounter with truly creative poetry produces not an experience of "I have never thought of this!" but an experience of "I have always thought this but could never put it so exactly!" The thought I encounter is thus the very image of my mind and true poetry merely gives my very own thought back to me. ${ }^{40}$

The paradoxical task of poetry is further elucidated in the passage on language where - apart from developing the dress metaphor as discussed above - Pope also introduces another simile, that of the prism. This simile is a further instance of Pope's deployment of the imagery of light and thus its primary function, as we would expect, is to explain how the prism of "false eloquence" (language, the same) obscures the plain light of Nature (the other).

False Eloquence, like the Prismatic Glass, Its gawdy Colours spreads on ev'ry place;

The Face of Nature we no more Survey,

All glares alike, without Distinction gay:

But true Expression, like th' unchanging Sun,

Clears, and improves whate'er it shines upon, It gilds all Objects, but it alters none.

$(311-7)$

The mechanism of pride is clearly perceivable in Pope's use of the image of the prism here. The prism, as false eloquence, stands in the way between the sun and what it shines on. It should mediate the light as directly as possible, but instead of doing this, it draws attention to itself, to its own "gawdy Colours," and thus stains the white light and blurs our sight.

Apart from this negative function, however, the prism image is also used here to explain, by a logical and metaphorical contrast, the nature of "true expression"; that is to say, the nature of the poetic task. "[T]rue Expression" is introduced in this passage as the remedy for the pride of "False Eloquence" and it is compared to the

39. Attridge, "Innovation, Literature, Ethics," p. 24.

40. See on this Attridge, The Singularity, p. 46. 
JÁNOS BARCSÁK

sun itself. We have seen in the section on "Nature as the Other" how this metaphorical identification between poetic expression and the sun forms an implicit paradox in the Essay, the sun image being associated both with Nature and with the poetic expression of it. If we now examine the more particular context in which this metaphorical identification appears, we will notice that it only further confirms the paradoxical act/event structure of creativity, highlighting what I have called in this section the double paradox of the poetic task.

What we first notice when we examine this more particular context is that the use of the sun image to represent true expression is no less striking here than it is in the context of the whole of the Essay. The phrase "true expression" obviously refers to the deployment of the poetic medium (the same) and we would therefore not expect it to be connected with the image of the sun which is here - as elsewhere in the poem - the representation of the source, Nature, the other. If false eloquence is compared to a prism, it would perhaps be more appropriate to contrast this prism to the clear glass of true expression; and indeed if we replace the sun image here with that of a clear window, we do not run into any contradictions either in this passage or in the whole of the poem. Pope's point is that poetry, unlike the prism of false eloquence, should allow the light of the sun to come through without obstruction, and this can in fact best be compared to the effect of a clear window. It is also quite in accordance with Pope's meaning here and elsewhere that the ultimate task of the poet is to clear the window, to make the poetic medium entirely transparent. Only if this is achieved can poetry come to fulfil its function, which is to provide unmediated access to the other. Only a clear window can provide us with a pure, distortionfree vision of the naked Nature.

We cannot assume, however, that Pope's use of the sun image instead of the more appropriate and also implicitly present window image is just accidental. By implying the clear glass image and then replacing it with the image of the sun he in fact draws attention to what I have described as the second paradox of the poetic task, the paradox that even though the same is defined as the opposite of the other, the other can still only come to us by and in the same. When the poetic medium (the same) is successfully eliminated, when it ceases to be itself for the sake of the other, when it becomes the clear window of true expression, then it in fact does not disappear but in its self-annihilation becomes more than itself: it itself becomes the source of light, it becomes the light of Nature in which alone things can become visible. This, however, does not mean the elimination of the first paradox: when poetry becomes thus successful, this success is always only achieved at the cost of self-annihilation. What poets achieve can only ever be a negative achievement: as far as their conscious activity is concerned, poets can only be successful in getting rid of their own "gawdy Colours," in not altering the 
objects that they make visible. ${ }^{41}$ If this negative achievement is accomplished, however, then the event of creativity can take place and poetry can become the light of Nature itself in which alone things can appear what they really are.

\section{"Those Rules of old"}

Art and the Rules are presented in the Essay's table of contents conjointly as means of improving judgment and they are described as being "but methodis'd Nature."42 Pope's presentation of these terms is, therefore, immediately connected to what has been described above as the paradoxical poetic task. If true expression is achieved, then - as we have seen - Nature itself becomes part of a work of art, it becomes "methodis'd Nature," and this is what Pope equates with Art and the Rules. We could say, therefore, that what Pope ultimately means by Art and the Rules is the positive aspect of the fundamentally negative achievement of "true expression," or to put it in another way - the result of the negative task. Art and the Rules are Nature (the other) itself as it has become part of a human-made object, the work of art. This is succinctly expressed in the famous couplet which introduces in the poem the concept of the Rules and which echoes the table of contents: 43

Those RULES of old discover'd, not divis'd, Are Nature still, but Nature Methodiz'd. . .

The word "Methodiz'd" does not imply here more order, for how could Nature be better ordered than it actually is?. Nor does it imply more abstraction, for whatever is made abstract ceases to be natural. What it implies is simply the paradoxical fact that Nature, which in itself is opposed to anything that is made by a human being, has become part of a work of art, that the other has come into the same. In this way Art and the Rules are no more and no less than Nature, and they are no more and no less than "true Expression." They represent positively the impossible and fundamentally negative unity of these two.

It is no wonder, therefore, that Pope's treatment of Art and the Rules - as I will try to demonstrate in this section - reflects and is grounded on the same ethical foundation as the concepts of Nature and Expression. Moreover, as I will also try to show, by the use of these concepts Pope also adds a new perspective on his ethical

41. That Pope has not departed from this pattern is also indicated by the fact that the next line after this passage contains the emphatic reestablishment of the dress metaphor: "Expression is the Dress of Thought" (318).

42. Pope, Pastoral Poetry, p. 237.

43. This echoing is of course not to be understood literally, since the table of contents was added to the poem only in its 1736 edition (Pope, Pastoral Poetry, p. 237n.). 


\section{JÁNOS BARCSÁK}

foundation. By highlighting the positive side of the fundamentally negative and paradoxical unity of Nature and expression (the other and the same) he incorporates in his argument the practical perspective. In other words, through the use of the concepts of Art and the Rules he does not only describe the paradoxical experience of creativity but also discusses how the negative task of eliminating the same in order to let the other come can be achieved. In this respect Pope goes beyond the scope of Attridge's treatment of creativity, and I will attempt to show here how this can be seen as a creative extension of the Attridgean scheme.

The concept of Art is introduced in the Essay immediately after the concept of Nature: "Art from that Fund [Nature] each just Supply provides, / Works without Show, and without Pomp presides..." (74-5). The exact grammatical function of the phrase "from that Fund" is ambiguous in the first line of this couplet: it can either qualify "Art," in which case the meaning of the first line is that only that art which derives from nature's fund provides "each just supply"; or it can modify the verb "provides," in which case the meaning of the line is that any "just supply" that art provides comes from the fund of nature. In either case, however, it is clear that a complete continuity between Art and Nature is suggested, which is further stressed in the second line of the couplet where we learn that Art works exactly as Nature does: it always presides but without show or pomp. ${ }^{44}$ This idea is further developed in the metaphorical contrast between body and soul presented in the passage that comes immediately after the couplet above:

In some fair Body thus th' informing Soul

With Spirits feeds, with Vigour fills the whole,

Each Motion guides, and ev'ry Nerve sustains;

It self unseen, but in th' Effects, remains.

44. The fact that Pope meant this identification between nature and art seriously is also borne out by the history of the composition of this passage. It seems that in the original version of the poem the connection between nature and art was merely an analogy. Instead of the couplet above Pope wrote: "That art is best which most resembles her [Nature], / Which still presides, yet never does appear" (Pope, Pastoral Poetry, p. 247). In 1716 this couplet was replaced by the final version (the one above) in which Pope makes the connection between nature and art more than just a superficial analogy. The editors of the Twickenham Edition suggest that the main reason for this change was that Pope wanted to get rid of the expletive "does." I think, however, that the alteration can also be seen as reacting in an instructive way to Dennis's criticism (Dennis, p. 404), which pointed out the contradiction in that "In the fifth Line of this Page it was Nature that / Life, force and beauty must to all impart. / And here in the 1oth we are told that 'tis Art that / With Spirit feeds, with Vigor fills the whole." This apparent contradiction is eliminated by Pope's direct identification of Art with Nature in the final version. 
Just as Nature is the Soul, that is to say, the perfect order, of physical objects (the Body), so Art - the passage points out - is the perfect order (the Soul) of the Body of words and ideas, of the poetic medium. It exists as the "trueness" of "true expression."

This use of the Body and Soul dichotomy can of course be easily recognized as yet another version of the same/other dichotomy and thus the concept of Art is immediately anchored in the ethical commitment that I think underlies the whole of Pope's poem. More specifically, what Pope draws attention to here is something that Derek Attridge frequently stresses in his account of creativity: that the other is never itself fully present but is only retrospectively identifiable as the other after it has become assimilated in the same. 45 Similarly, what Pope emphasizes in this passage on Art is that the Soul (Nature, Art, the other) is never in itself visible, it can only become manifest indirectly, through the Body (the same). What we experience when we encounter a work of creativity is always only the same (Body) but this same can be experienced as a singular otherness if, and only if, it is successfully refashioned by the other (Soul). If the invisible Soul (Nature, Art, the other) does not "prevail," if it does not entirely permeate and subdue the Body (the same), if the Body (the same) does not cease to be a body, it can never be beautiful. However, even when the event of creativity occurs, even when the Body is entirely subdued and thus becomes inspired (in-Souled), when the same ceases to be the same and allows the other to shine through it, the Soul (Art, Nature, the other) still remains "unseen." We deduce its presence only from "the effects"; that is, from the particular refashioning of the Body that we encounter and that - we conclude - can only have been achieved by the agency of the Soul. The Soul (Nature, Art, the other) is thus never actually present or experienced, it can only retrospectively be identified as that which "in th' Effects, remains."

This introduction of the concept of Art as a never in itself manifest but retrospectively identifiable presence lays the foundation of Pope's treatment of the Rules which, as we have seen, he directly identifies with Art. In fact it is, I think, only on this foundation that we can make sense of Pope's otherwise rather paradoxical discussion of this all-important concept in the Essay. It is, for example, only on this basis that we can make sense of what is perhaps the most conspicuous paradox in Pope's treatment of the Rules: the self-contradiction in that whereas the Rules are by definition mechanically repeatable patterns, and should therefore belong to the realm of the same, Pope frequently stresses that this is a misunderstanding of their true nature and function. Although he emphasizes the strict, arbitrary authority of the Rules, he takes special care to contrast his conception of them with "the Rules

45. Attridge, "Innovation, Literature, Ethics," pp. 23-24. The idea is of course one aspect of what I referred to in the previous section as the second paradox of creativity. 


\section{JÁNOS BARCSÁK}

each Verbal Critic lays" (261), which he labels as merely "dull Receipts how poems may be made" (115).46 Paradoxically, therefore, Pope maintains that, just as Nature has, the Rules have once and for all "fix'd the Limits fit" (52), but he also emphasizes that this does not mean that they can be abstracted, formulated in an unchangeable, definitive system. This seeming paradox is explained in the passage that follows the first mention of the Rules in the Essay ("Those RULES of old"):

Hear how learn'd Greece her useful Rules indites, When to repress, and when indulge our Flights:

High on Parnassus' Top her Sons she show'd,

And pointed out those arduous Paths they trod,

Held from afar, aloft, th' Immortal Prize,

And urg'd the rest by equal Steps to rise;

Just Precepts thus from great Examples giv'n,

She drew from them what they deriv'd from Heav'n.

The word "indites" suggests the unquestionable authority of the Rules of the classics; however, when Pope explains how ancient Greece dictates its "useful Rules," it becomes clear that he does not mean explicit, abstract, unchangeable prescriptions. The Rules primarily exist in and as the successful artwork. The work of art is the ultimate fact and because it undeniably exists, we conclude that there must have been some Rules by which it came into being. These Rules, therefore, cannot be abstracted from the artwork itself; they exist as those paths that (retrospectively) explain how it was possible to reach the top of Parnassus, to bring into being the successful work of art. However, since Parnassus can be ascended by these paths alone, since any work of art can be brought into being only by Rules, the Rules are not merely rationalizations of something that can very well exist without them. They essentially belong to the being of the work of art; in this sense they are the work of art. Thus the function of the Rules is not to prescribe or provide an abstract recipe of success, but to urge emulation by pointing up the successful work of art itself in the act of rationalizing how its greatness has been achieved.

This conception of the Rules can also explain another, even more striking, paradox in Pope's treatment of this issue, his discussion of poetic "licence":

If, where the Rules not far enough extend,

(Since Rules were made but to promote their End)

Some Lucky Licence answers to the full

Th' Intent propos'd, that Licence is a Rule.

46. A distinction which David Fairer compares to that "between Natural Law and mere legalism” (David Fairer, The Poetry of Alexander Pope (London: Penguin Books, 1989), p. 35). 
These lines and the passage in which they appear (141-80) are usually glossed in Pope criticism as an expression of the poet's response to Longinus and to the evolving critical tradition based on the sublime. As the editors of The Twickenham Edition put it,

The belief that irregular genius is preferable to a cold and flat correctness, that there is a criticism by taste as well as by rules, that the success of a work of art may depend upon a quality difficult to define, a je ne sais quoi, that a criticism of beauties is preferable to a criticism of faults, that departures from poetic rules are like irregular but pleasing objects in the natural world, is emphatic in the lines, and declares the lack of rigour with which Pope adhered to the "Rules." 47

This is no doubt true of this passage. However, I think it would be a mistake to look at these thoughts as an incongruous part of Pope's treatment of the Rules. In fact these ideas fit in perfectly with the ethical foundations that underlie Pope's overall conception. If we examine the two couplets quoted above, it will become clear that what they emphasize is once again that the ultimate fact of creativity is the successful work of art. It is the end; the Rules function merely as a means to achieve this end. If a licence, that is, a deviation from the Rules, serves this end better than the Rules themselves, then that licence is to be preferred to the Rules. However, by insisting that "that Licence is a Rule," Pope stresses once again that, Rules are indispensable in any creativity. If the end is achieved, if the work of art has come into existence, then this could only have happened by some rule. The licence by which the work of art was produced is, therefore, also a rule and has always already been one, but we have not been aware of it until it manifested itself in this particular work of art, in this singular otherness.

What follows from this is that it is not in itself wrong that we tend to generalize rules, to abstract them, to formulate systems out of them. It is not wrong as long as we keep in mind the genealogy of the Rules; that is, that they are only retrospectively identified as means of accounting for the existence of the work of art. Derek Attridge's description of this paradoxical relation between Rules and the work of art is once again revealing. When discussing the experience of reading he writes:

An essential part of a full response to a text ... is a deduction of its modus operandi, an accurate understanding of the repeatable rules according to which the text operates as a meaningful entity. ... While generalizable norms are involved from the start ... it is only retrospectively that we can

47. Pope, Pastoral Poetry, p. 255n. 


\section{JÁNOS BARCSÁK}

extract them as norms (and thus objectify the transition from the other to the same), although even this hypostatization remains revisable. ${ }^{48}$

Objectifying the transition from the other to the same, from Nature to the work of art, is rule-formation and such rule-formation is indeed indispensable in any account of creativity. However, any system of rules thus formed must remain revisable, must maintain the status of a hypothesis in relation to the fact of the work of art. And it is in part this point that Pope's paradox of licence and Rules expresses. If any work of art comes into existence which cannot be accounted for from existing Rules; that is, if any work of art is created by a deviation from the Rules, by a licence, then the work of art must be accepted as the ultimate fact, and the Rules must be revised. On the other side, however, Pope's paradox also emphasizes that when we alter the Rules, it does not mean that we admit chance into our account of the work of art - far from it. Any work of art, as we have seen, can only exist by Rules, "generalizable norms are involved from the start" - the Rules are essentially the work of art. What happens when an apparent "licence" achieves the end simply demonstrates the fact that we can never be fully aware of all the Rules that contribute to the making of works of art. Thus what appears at first to be a licence or even a fault turns out in the end to be a Rule that we have not been aware of previous to the encounter with that particular work of art, that singular otherness. The beauty a great work of art snatches "beyond the reach of Art" (155) will, therefore, in the end turn out not so much to go beyond Art as to reveal new reaches of it that we have not previously been conscious of.

What I have tried to show thus far is that Pope's treatment of Art and the Rules is fundamentally grounded on the responsibility for the other. These foundations, however, directly lead us to the issue of praxis, to Pope's discussion of how the Rules can bring about, or at least facilitate the event of creativity. The Rules, we have seen, are ultimately the successful work of art. As such, however, they belong to that part of the experience of creativity which rationalizes, objectifies the process in which Nature becomes part of a human-made artwork, in which the other comes into the same. Therefore - alone from the aspects of creativity that have been discussed so far - they lend themselves naturally to abstraction, to generalization, to systematic formulation. And this, as we have also seen, is not in itself wrong: "just

48. Attridge, "Innovation, Literature, Ethics," p. 25. In his restatement of these ideas in The Singularity of Literature (p. 81) Attridge stresses that the rules by which a work is meaningful are not inherent in the art object itself and can vary from age to age depending on the particular cultural situation. Although this aspect is clearly not emphasized in the Essay, I think that Pope's treatment of the licence/rule relation allows for the inclusion of such a view and leaves the overall structural similarity unchanged. 
Precepts" can and indeed must be drawn from "great Examples." We have to generalize and abstract rules from the great examples of the classics if we want to emulate their achievement. The act side of the act/event structure of creativity is unimaginable without such abstraction and generalization. Pope emphasizes thus that an essential part of our effort to bring the wholly new into existence must necessarily be that we learn and use explicit patterns, repeatable and mechanical rules.

This aspect is certainly less emphatic in Derek Attridge's account of creativity, as well as in most modern discussions of alterity, than it is in Pope's. It is, however, by no means a deviation from the ethical foundations of true creativity which Derek Attridge so suggestively outlines and which, as I have tried to show, also underlies Pope's Essay. I would rather look at this aspect of Pope's treatment of creativity as a creative extension of the Attridgean scheme. 49 For no matter how consistently Pope emphasizes the practical function of explicit, generalizable rules, he never loses sight of two crucial things: (1) that all abstract formulations of rules are valuable only insofar as and to the extent that they derive from successful works of art; that is, that they are based on encounters with the other; and (2) that no practical rule can ever affect Nature (the other); they only function as means of regulating, controlling the same (the poetic medium) in order to allow the other to come.

These points are made clear in the Essay immediately after the introduction of the Rules, more particularly in the passage on "learn'd Greece" quoted above. We learn here that "just Precepts" can only be drawn from "great Examples" and that these precepts are valuable not because they impose limitations but because by imposing limitations they show us the path to achieve the highest. Besides, we also learn that the lesson "learn'd Greece" teaches us by its "useful Rules" is not how to bring Nature into the poetic medium (the other into the same), but rather "When to

49. One explanation for the apparent differences and the essential similarity between Attridge and Pope's accounts of creativity could be their different approaches to the "same." Whereas Attridge stresses that the arrangement of the same is always dependent on a particular culture and ideoculture, and the way it poses obstacles to (and thereby constitutes) the other is thus ungeneralizable, Pope seems to insist that no matter how different the cultural situation, the same will always get in the way of the other in very similar ways (see below). I think that both these approaches to the same are equally justifiable. As Shelley says in his superb lyric, "The Cloud" - which is based on an image remarkably similar to Pope's cloud of pride and which I think can be interpreted as Shelley's treatment of the "same" - the Cloud is "Like a child from the womb, like a ghost from the tomb": it is both something wholly new and at the same time the same old thing. It is indeed in this way that we are always frustrated in our best efforts (or even in our most trivial ones such as compiling shopping lists or trying to avoid misprints) by the law of the same: we can never prepare for it beforehand, because it is always something totally unexpected; however, when it has happened, it always turns out to have been just the same old mistake. 


\section{JÁNOS BARCSÁK}

repress, and when indulge our Flights" [italics added]; that is, how to comport ourselves, how to regulate the same, in the face of Nature, the successful work of art, the other.

This view of the practical aspect of creativity is further confirmed in another famous passage in the Essay on Art; in the couplet where the function of Art is explained through the analogy of dancing. This analogy - although it only occurs in a single couplet - provides, I think, a perfect image to grasp the proper practical function of the Rules. The couplet in which the dance simile appears is this:

True Ease in Writing comes from Art, not Chance,

As those move easiest who have learn'd to dance.

$(362-3)$

We notice here once again how Pope stresses the significance of conscious study and effort in the act of creativity. Art is associated with learning: just as the steps of the dance must be learnt and practiced before one can become a good dancer, so the Rules must be consciously studied and applied if one wants to be successful in poetry. This, however, is a requirement not because any rules can teach one how to dance well or be a good poet, but because, as we have seen, the Rules are always directed at the regulation of the same (the body in dancing and the poetic medium in writing). They are thus a necessary part of the "act" aspect of the act/event structure of creativity, of that aspect which we can consciously control, and which - although it cannot bring about the event of creativity - is indispensable in making it possible. It is indispensable precisely because Nature can only come to us in the successful artwork, because the other only exists in and as a particular refashioning of the same. And that refashioning will not come by chance; it will not come without conscious effort, without learning and following the Rules. If one is told just to move naturally on the dance-floor, one will be at a loss. Without learning and practicing some steps one just cannot control one's body as a dancer. And similarly, we will not achieve a natural effect in writing without consciously learning and practicing the Rules.

No matter how much Pope stresses the necessity of conscious study and effort, however, it is evident in his use of the dance metaphor, too, that he never forgets that true creativity always comes from the other. As the couplet above makes it clear, the aim of all acquisition and application of explicit rules must always be the "true ease" and complete naturalness of the successful work of art. The aim must, therefore, always be something that cannot be controlled by any conscious effort or explicit rules; it must always be the event of creativity. What Pope stresses is merely that this event will not take place without Art, without a proper application of the Rules.

In this discussion of the practical aspect of creativity we have come rather far from what I identified at the beginning of this section as Pope's basic insight about 
the Rules: that the Rules are the successful work of art. This insight, however, is I think not contradicted by Pope's emphasis on learning and conscious effort either. What he points out by his use of the dance metaphor is, as we have seen, that success in poetry (just as in dancing) comes from Art; that is to say, that the event of creativity takes place if and only if the Rules are properly applied. He emphasizes furthermore that Art, the proper application of the Rules, can only be achieved by making a conscious effort, by learning and practicing explicit, repeatable, mechanical patterns. However, he does not say that any learning, any mastery of explicit patterns can guarantee that the Rules are applied properly. The Rules, just as in his previous discussions of them, go beyond any explicit system in which they could be totalized. The Rules no doubt are made up of repeatable, learnable patterns, but they are also more than any totality of these patterns. Thus while one can learn and master any number of precepts and rules, one can never master the Rules. The only sure test of whether the Rules have been applied properly is the success of the work of art, which remains the ultimate fact of creativity. If "true ease" and complete naturalness have been achieved in dancing or in writing, then, and then alone, can we be sure that the Rules have been properly put to use.

\section{Nature, Expression and the Rules: a Holy Trinity}

The image of dancing can thus serve as a perfect expression of the significance and practical function of the Rules. This image, furthermore, can also reveal how the Rules are connected to the two other central concepts of the Essay that have been examined above: Nature and true Expression. Even though the dance simile is not as fully developed as some of Pope's other images, it clearly conjures up the body/soul metaphor and can thus create a link between these three key concepts in the Essay. In this section, therefore, I will attempt to summarize what has been said about these three concepts and their relations by dwelling a little longer on the analogy of dancing.

As we have seen in the discussion of the image of dancing above, the end of all creative activity is "true Ease," which can only be thought of as an event. This event happens of its own accord; however, it will not happen unless we learn the Rules and work hard to apply them. The proper application of the Rules in the case of dancing is always to affect the medium of this art, the Body, and by controlling, regulating this medium to make it capable of receiving the other (the Soul). The situation is, therefore, very similar to what we saw in the discussion of "true Expression." The aim of true expression is to bring Nature (the other) into the poetic medium (the same) by regulating, controlling and even eliminating the latter, by making the poetic medium entirely transparent. These ideas are perfectly conveyed 
JÁNOS BARCSÁK

by the dance metaphor, too. The medium of dancing, the Body, is primarily characterized by its inertia; the body is a body insofar as it is heavy. In order to achieve the aim of creativity ("true Ease") one must, therefore, work against the body, annihilate it entirely so that it gives way to its opposite: the Soul (Nature, the other). Paradoxically, however, it is only by and in this annihilation of the Body that the Soul can manifest itself. In the art of dancing thus the Body must be regulated and consciously controlled so that by annihilating itself it can become all Soul and thus provide the only possibility of manifesting the Soul.

So far this is just another beautiful representation of the paradoxes of true expression. What the dance metaphor's emphasis on conscious study and practice adds to this is the insight that the self-annihilation of the same (the Body, the poetic medium) which is the essence of "true Expression" can be achieved by learning and applying the Rules. The proper way of regulating and controlling the Body in dancing does not come spontaneously. One must learn how to defeat the inertia that affects and determines the Body in its being a Body. Since the Body is affected by gravitation in regular ways, we can form laws as to how to defeat this inertia. And this is how we can connect the Rules to what has been said about "true Expression" above. Just as the Body as the medium of dancing is essentially characterized by its being affected by inertia, so the poetic medium is determined in its being by an essential sluggishness and inertia that Pope generally terms pride. And just as gravitation affects the Body in systematic ways, so pride is a systematic error. Thus the Rules in dancing, in writing and in all creative activities are no more and no less than the systematic, reproducible and learnable patterns that counteract the systematic entropic forces that essentially characterize the medium of the creative activity. They serve to eliminate the Body (the self, the poetic medium, the same), not to create the Soul (Nature, the other). However, by binding the Body they do liberate the Soul. Their proper function is thus not to limit us, but by curbing what is sluggish and inane within us to free us to receive what cannot be forced to come, but what - like the light of the sun - gives itself if it finds no obstacle in its way: the Soul, Nature, the other.

Thus what we can learn from the dance metaphor and from Pope's treatment of the practical in general is that without the Rules there is no true Expression. Similarly, as we could see in the discussion of Expression above, Nature cannot exist for us without true Expression. We can conclude therefore that Nature is true Expression and true Expression is the Rules. These three form a kind of "holy trinity" each representing a different aspect of the same indivisible unity. This insight is powerfully expressed by Pope in one of the most paradoxical passages of the Essay, the passage on Virgil, whose paradoxes, however, are resolved in the light of what has been said about the connection between Nature, Expression and the Rules. 
When first young Maro in his boundless Mind

A Work t' outlast Immortal Rome design'd,

Perhaps he seem'd above the Critick's Law,

And but from Nature's Fountains scorn'd to draw:

But when t'examine ev'ry Part he came,

Nature and Homer were, he found, the same:

Convinc'd, amaz'd, he checks the bold Design,

And Rules as strict his labour'd Work confine,

As if the Stagyrite o'erlook'd each Line.

$(130-8)$

What Virgil realized, according to this passage, is that what he had thought of previously as an independent Nature can only exist and has always already existed as true poetic expression, as artistic creation. And the conclusion that he draws from this realization is that he must learn and follow the Rules without which no true Expression and thus no access to Nature could exist.

\section{Conclusion}

One might object to such a reading of Pope's Essay that after all the ideas and even the imagery that I have examined above can be traced back to their sources in Pope's vast readings in the neo-classical critical tradition. The idea that the Rules are methodized nature goes back, for example, to René Rapin's Reflections on Aristotle's Treatise of Poesie and was formulated both by Dryden and Dennis before Pope; $5^{\circ}$ the paradoxes of licence and rule derive from Roger de Piles's The Art of Painting and were also expressed by Boileau; ${ }^{51}$ and the image of dress as a representation of poetic expression was a commonplace of neo-classical criticism, having been used previous to Pope by the Earl of Roscommon, by Roger de Piles and by Dryden..$^{2}$ Similarly, what I identified above as meaning-productive paradoxes of the text and what I relied on so heavily for my claim that the Essay is essentially an account of the experience of creativity can also be explained as merely deriving from Pope's use of his sources. As the editors of the Twickenham Edition point out, Pope used highly eclectic material for the composition of the Essay, attempting to harmonize the apparently opposing attitudes that his various sources embraced and

50. Pope, Pastoral Poetry, p. 249n.

51. Pope, Pastoral Poetry, pp. 256-7n.

52. Pope, Pastoral Poetry, p. 273n, pp. 274-5n. 


\section{JÁNOS BARCSÁK}

this, as Audra and Williams conclude, "was bound to appear at times vague and paradoxical." 53

To these objections we might simply answer that after all neo-classical criticism, just like any treatment of the literary, must also involve some account of creativity. Therefore, if we maintain that creativity always arises from the coming of the other, then we can conclude that Pope's sources must also have responded to this fact. Their insights and even their apparently contradictory principles might thus very well derive from a genuine response to the other. Indeed when one reads Pope's sources, for example such critical masterpieces as Dryden's Essay of Dramatic Poesie, one is constantly aware that the focus of these works is not so much on rule and precept as on that unaccountable but also undeniable sense of perfect naturalness which characterizes the successful work of art; that is to say, on the otherness we experience in a genuine response to creativity. If, therefore, Pope used the material provided by the neo-classical critical tradition, it is by no means a proof against the Essay's being based on a responsible relation to the other. One might say that Pope discovers these ideas, not devises them, but this certainly does not prevent him from selecting that part of his sources which best express a genuine commitment to the other, nor does it prevent him from embracing contradictory attitudes which, being transformed into the paradoxes of the Essay, further confirm this fundamental commitment.

Although this answer to the above objections might legitimate my approach to the text, it certainly does not do full justice to Pope's achievement. For even if we can trace all the ideas expressed in the Essay back to their sources, the poem - as commentators seem generally to agree - still cannot be reduced to these sources. 54 It cannot be reduced to them precisely because although Pope may indeed present in the Essay "what oft was Thought," he presents it so that it was "ne'er so well Exprest." True expression - as we have seen - is a genuine response to the other and as such it brings into being the wholly new. Thus while it is no doubt true that Pope selects, organizes, responds to material that he found in his readings - indeed who can do without this? -, it is also undeniable that with his true expression he in fact creates, brings into being the wholly new. To apply Johnson's praise of Dryden we could say about the relation between Pope and his raw material that "he found it brick and he left it marble"; or we could even paraphrase this to emphasize the essential transformation that true expression achieves and say that he found it coal

53. Audra and Williams, "Introduction" to An Essay on Criticism in Pope, Pastoral Poetry, pp. 211-2.

54. Cf. for example Audra and Williams, "Introduction" to An Essay on Criticism in Pope, Pastoral Poetry, p. 223. 
and he left it diamond. Just as under great pressure coal is transformed into diamond, so under the influence of poetic creativity Pope's common raw material is crystallized in the poem into an exceptionally transparent and precious form. If we analyze it, we can of course identify its raw material, just as we can truly say that diamonds are made of carbon; but to stop at this level would be a major oversight and would certainly not be responding creatively to the text. A responsible reading of the Essay must also respond to the singularity of the poem: besides identifying its material (which can indeed be as common as carbon), it must also account for the uniqueness the treatment of this material creates (the transparency, the brilliance, the special value of the diamond). It must, in other words, "[s]urvey the Whole" which can in no way be explained from tracing the origin of its individual parts.

In my attempt to emphasize the singularity of the whole I have inevitably fallen short of this ideal for at least two reasons. Firstly, because I did not discuss - for lack of space - all the aspects of the Essay that are relevant to my approach. I have omitted, most conspicuously, the discussion of the issue of criticism which is no doubt a central issue in the poem and which could otherwise very well fit in with what I have tried to reveal as the ethical foundation of Pope's Essay. Secondly, I have fallen short of doing justice to the whole in Pope's poem precisely by postulating a whole and thereby confining the poem's richness within the bounds of my approach. Although, as I argued in the Introduction to this paper, this is an inevitable move and the necessary price one has to pay for any responsible response to a work of creativity, I want to stress once more that this is nevertheless a reduction and that I do not believe that my approach can in any way contain the Essay as a whole. However, what I do hope to have achieved by the comparison I have drawn between the poem and Attridge's theory of creativity (a theory to which once again I cannot claim to have done full justice) is the demonstration of my original claim that Pope's Essay is a vital text. Three hundred years after its first publication it remains "a friend to man," or, in Attridge's terminology, it continues to be a most intimate stranger. 55 It keeps communicating itself to us in our world, in our time, challenging our entrenched and unreflected beliefs and enlightening us where we most need enlightenment.

55. Attridge, "Innovation, Literature, Ethics,” p. 26. 